\title{
De la formación de usuarios a la alfabetización informacional: propuestas para enseñar las habilidades de información
}

\author{
José A. Gómez Hernández \\ Universidad de Murcia \\ Facultad de Ciencias de la Documentación \\ Félix Benito Morales \\ Conselleria de Educació y Cultura \\ Generalitat Valenciana
}

\section{O.1. Resumen}

Analizamos la evolución conceptual de un servicio de las unidades de información, la "formación de usuarios", hacia los actuales modelos de "alfabetización informacional". Entendemos alfabetización informacional en dos sentidos: 1) desde el punto de vista de los usuarios, es el dominio de una serie de competencias o habilidades para obtener, evaluar, usar y comunicar la información a través de medios convencionales y electrónicos; 2) desde el punto de vista de las instituciones educativas y documentales, es el servicio y las actividades para lograr la enseñanza-aprendizaje de los conceptos, procedimientos y actitudes relativos al acceso y uso de la información. Tras formular el concepto de "alfabetización informacional" desarrollamos una serie de propuestas para la enseñanza de habilidades de información, tanto desde el punto de vista del sistema educativo como desde los sistemas bibliotecarios y documentales, que han de colaborar en esta tarea. En el sistema educativo obligatorio, además de la potenciación del uso didáctico de las bibliotecas escolares, es necesaria la formación permanente del profesorado en materia de habilidades de información, y la conversión de la "educación documental" en tema transversal o en materia optativa. En la educación superior hay que aprovechar las posibilidades de formación a través de tutoriales web para la capacitación en el acceso y uso de la información científica especializada; intensificar la cooperación con los docentes y regularizar la formación de usuarios integrándola en lo posible a través de asignaturas optativas o de libre configuración. (Autor)

Palabras clave: Formación de usuarios. Alfabetización informacional. Educación. Habilidades informativas. 


\subsection{Abstract}

The conceptual evolution of information services from "user education" entities to "information literacy" ones is analysed. Information literacy is understood in two senses. In the first one, it is the mastering of several skills to obtain, evaluate, use and communicate information through conventional and electronic ways. Secondly, it consists of the service and activities designed to achieve the teaching and learning of the concepts, procedures and attitudes related to information access and use. After formulating the concept of information literacy, several proposals for teaching of information abilities are developed, both in the Educational and in the Library Systems. In the Basic Educational System, besides the intensification of the didactic use of school libraries, it is necessary to provide the teachers with longlife learning and training on this topic, and transform Information Literacy in a cross subject. In higher education, it is necessary to make use of web tutorials for training in the access and use of specialized scientific information, to intensify the cooperation of librarians and faculty, and to regulate user education, integrating it as much as possible as an optional subject in the curricula. (Author).

Keywords: Information literacy. Information abilities. User education.

\section{De la formación de usuarios a la alfabetizacion informacional}

Las bibliotecas y en general las unidades de información (BUI) han entendido tradicionalmente la formación de usuarios como el servicio de dar a conocer la institución, sus servicios y sus recursos de búsqueda documental. En este sentido, ha sido normalmente una orientación para el uso, y en algunos casos una instrucción bibliográfica-documental, cuyo nivel dependía del tipo de usuario y del tipo de institución.

Una razón de la necesidad de la formación de usuarios ha sido la compleja organización de la información documental en nuestras instituciones, que han tenido sistemas clasificatorios difíciles, poco señalizados y facilitados conceptual y gráficamente. En este sentido, la progresivamente mayor disposición de las BUI para facilitar el uso, ha ido haciendo que se simplificara el acceso, y que su diseño facilitara la consulta y uso tanto de las instalaciones como de la colección y los productos de búsqueda bibliográfica. Esta simplificación ha ido reorientando los contenidos de la formación de usuarios. La mejor señalización, la amigabilidad de los interfaces de consulta o el acceso directo a las colecciones, van guiando y facilitando el uso, y lo que ahora va siendo necesario enseñar es qué nuevas fuentes existen, el uso de las bases de datos especializadas, las posibilidades de las búsquedas expertas, etc.

Pero no nos equivoquemos: el que apartemos las complejidades innecesarias de los procedimientos de acceso y consulta no implica que las personas sepan uti- 
lizar y aprovechar mejor la información para su propio conocimiento y su actuación. La información en general, y la científica en particular, es cada día más compleja, por factores como el crecimiento del volumen de la documentación en múltiples soportes y vías de acceso, el rápido cambio y la mediatización tecnológica del conocimiento. Y ello lleva a la necesidad creciente de habilidades de información, que hagan a las personas capaces de aprender durante toda la vida y adaptarse a los cambios.

Las habilidades que se exigen en la era electrónica son de magnitud diferente a las de la época de la imprenta: "La identificación y localización de recursos individuales era una tarea finita, dentro de los límites fijados por los fondos existentes, y considerada sobre todo como la habilidad de navegar por los catálogos de la biblioteca y los sistemas de clasificación de las estanterías. Identificar y localizar recursos en un mundo electrónico, por otro lado, puede que sea una tarea casi infinita. A medida que continuamos haciendo la transición de una era tradicional a una electrónica, se intensifica la necesidad de habilidades de información" (Barry, 1999) (Figura 1).

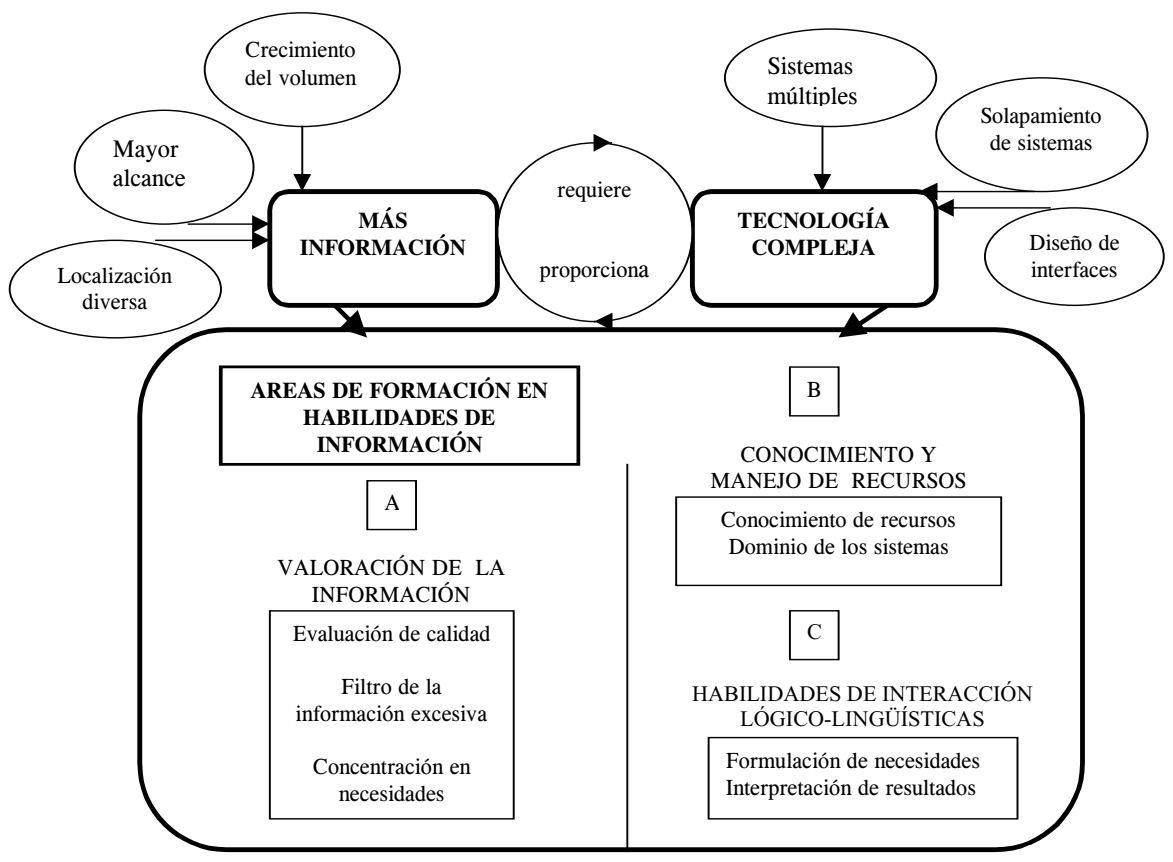

Figura 1. Necesidad de habilidades de información

Scire. $7: 2$ (jul.-dic. 2001) 53-83. 
Lo que necesitan los individuos no es sólo saber usar las BUI, sino dominar las habilidades y estrategias para informarse y usar la información, lo que implica conocer las fuentes, saber aplicar de modo inteligente los procedimientos para obtener información de ellas. En esta concepción lo que se abarca va más allá de la tradicional formación de usuarios, porque no nos preocupa sólo la información documental accesible en o desde las BUI, y nos implicamos no solo en enseñar las habilidades de buscar y localizar, sino también las de comprender, usar y comunicar la información y lograr conocimiento. A la enseñanza-aprendizaje de estas habilidades la denominamos "alfabetización informacional".

\section{El concepto de alfabetización informacional}

Por alfabetización informacional entendemos un proceso de aprendizaje mediante el cual uno identifica una necesidad o define un problema; busca recursos aplicables; reúne y consume información; analiza e interpreta; sintetiza y comunica eficazmente a otras personas; y evalúa el producto realizado. Una persona alfabetizada en información es aquella capaz de reconocer cuándo se necesita información y tiene la capacidad para localizar, evaluar, y utilizar eficientemente la información requerida (ALA, 1989), lo que le permite llegar a ser un aprendiz independiente a lo largo de la vida.

La alfabetización en información es mucho más que un paso lógico en la evolución de la instrucción en el manejo de las bibliotecas o de bibliografía; es mucho más que enseñar cómo usar la biblioteca. El objetivo de la alfabetización en información es crear aprendices a lo largo de la vida, personas capaces para encontrar, evaluar y usar información eficazmente para resolver problemas o tomar decisiones, usando o sin usar una biblioteca. Tanto si la información viene de un ordenador, de un libro, de un órgano de gobierno, de una película, de una conversación, de un póster, o de cualquier otro posible recurso, inherente en el concepto de alfabetización en información está la capacidad de examinar y comprender lo que se ve en la página o en la pantalla de la televisión, en un póster, en un dibujo, en otras imágenes, así como en lo que oyes. Aspiramos a enseñar y posibilitar el aprendizaje tanto de habilidades documentales como de pensamiento (Benito, 2000).

La alfabetización informacional es un objetivo global que implica y compromete tanto al sistema educativo en todos sus niveles obligatorios como a las instituciones documentales. Los documentalistas, como proveedores y organizadores de información para su uso, deben facilitar el conocimiento de las metodologías documentales que permiten su óptimo aprovechamiento, enseñarlas y simplificar los sistemas de recuperación de información teniendo en cuenta las necesidades y características del proceso de aprehensión de conocimiento de los usuarios. Una parte importante del valor añadido de las BUI en una etapa de aparente desintermediación en el acceso es la capacitación de los usuarios en el uso de la informa-

Scire. $7: 2$ (jul.-dic. 2001) 53-83. 
ción, que haga que el acceso autónomo a la misma no lleve a pérdidas de parte del conocimiento disponible, sino a un aprovechamiento satisfactorio y cómodo.

Para referirse al conjunto de contenidos relativos a este área, en el mundo anglosajón se utiliza principalmente el término "information literacy", y en el ámbito francófono, "maîtrise de l'information" (Bernhard, 1997) (1). Con la expresión "alfabetización informacional" traducimos literalmente la denominación anglosajona, y el uso del término alfabetización remarca que la tradicional alfabetización lectoescritora, es decir, la competencia para codificar, comprender y producir textos escritos ya no es suficiente, debiendo completarse y enriquecerse con el dominio de los medios documentales y tecnológicos que mediatizan hoy el acceso a la información, con las competencias necesarias para la comprensión de distintos tipos de textos en distintos formatos, la capacidad de integración de la información nueva en el propio sistema conceptual, la capacidad para comunicar el conocimiento producido de modo coherente con los distintos canales y posibles receptores. Si la alfabetización lectoescritora era la condición para una participación en la cultura de la época moderna nacida de la imprenta, la expresión "alfabetización informacional" o "alfabetización en información" apela de modo paralelo a su carácter de vía básica para una participación autónoma, crítica y reflexiva en la actual sociedad digital o de la información.

Aunque existen muchos modelos que describen las distintas habilidades abarcadas por la alfabetización informacional, que hemos recientemente descrito (Benito, 2000), utilizaremos para ello los estándares de la asociación americana de bibliotecarios escolares (AASL, AECT, 1998), que establecen además algunos indicadores del dominio de cada competencia (Figura 2). Vemos, por tanto, que la alfabetización informacional engloba tres tipos de conocimientos y habilidades (Benito, 2000):

- Para encontrar información: habilidades de localización y recuperación documental, y habilidades de manejo de equipos tecnológicos.

- Para usar información: habilidades de pensamiento, habilidades de estudio e investigación y habilidades de producción y de presentación.

- Para compartir y actuar éticamente respecto a la información.

En síntesis, las personas con alfabetización informacional:

- Son ávidos lectores y consumidores de información artística y cultural. Son pensadores críticos y creativos, aprendices motivados, e investigadores organizados. Usan la información responsablemente y son comunicadores eficientes. Colaboran con otros, tanto en persona como a través de las tecnologías en el diseño, desarrollo y evaluación de proyectos o productos de información. Con todo ello, sus habilidades en el uso de la tecnología de la información aumentan.

Scire. $7: 2$ (jul.-dic. 2001) 53-83. 
Categoría 1: Alfabetización en información: El estudiante con alfabetización en información:

Estándar 1: Accede a la información con eficiencia y efectividad.

Indicador 1. Reconoce la necesidad de información.

Indicador 2. Reconoce que la información exacta y completa es la basa de la toma de decisiones inteligentes.

Indicador 3. Formula preguntas basadas en sus necesidades de información.

Indicador 4. Identifica diversas fuentes potenciales de información.

Indicador 5. Desarrolla y utiliza estrategias acertadas para la localización de información.

Estándar 2: Evalúa la información de forma crítica y competente.

Indicador 1. Determina la exactitud, pertinencia y exhaustividad de la información

Indicador 2. Distingue entre hechos, puntos de vista y opiniones.

Indicador 3. Identifica la información errónea y engañosa.

Indicador 4. Selecciona la información apropiada para el problema o pregunta.

Estándar 3: Usa la información de forma correcta y creativa.

Indicador 1. Organiza la información para una aplicación práctica.

Indicador 2. Integra nuevos conocimientos mediante información nueva.

Indicador 3. Aplica información en el pensamiento crítico y la resolución de problemas.

Indicador 4. Produce y comunica información e ideas en formatos adecuados.

Categoria 2: Aprendizaje independiente: El estudiante que es capaz de realizar aprendizajes independientes y está alfabetizado en información:

Estándar 4: Busca información referente a intereses personales.

Indicador 1. Busca información relacionada con varias dimensiones de bienestar personal, como son intereses de estudio, el compromiso social, temas de salud y de ocio creativo.

Indicador 2. Planifica, desarrolla y evalúa productos de información y soluciones relacionadas con intereses personales.

Estándar 5: Aprecia y disfruta la literatura y otras expresiones creativas de información.

Indicador 1. Es un lector competente y automotivado.

Indicador 2. Deriva el significado de la información presentada de forma creativa en una variedad de formatos.

Indicador 3. Desarrolla productos creativos en diversidad de formatos.

Estándar 6: Se esfuerza al máximo por la excelencia en la búsqueda de información y generación de conocimiento.

Indicador 1. Evalúa la calidad del proceso y los productos de las propias búsquedas de información.

Indicador 2. Concibe estrategias para revisar, mejorar y actualizar los conocimientos obtenidos.

Categoría 3: Responsabilidad social: El estudiante que contribuye positivamente a la comunidad de aprendizaje y a la sociedad está alfabetizado en información y:

Estándar 7: Reconoce la importancia de la información en una sociedad democrática.

Indicador 1. Busca información de fuentes, contextos, disciplinas y culturas diversas.

Indicador 2. Respeta el principio de acceso equitativo a la información.

Estándar 8: Practica un comportamiento ético respecto a la información y a la tecnología de la información.

Indicador 1. Respeta los principios de libertad intelectual.

Indicador 2. Respeta los derechos de propiedad intelectual.

Indicador 3. Usa la tecnología de la información de modo responsable.

Estándar 9: Participa efectivamente en grupos para buscar y generar información.

Indicador 1. Comparte el conocimiento y la información con otros.

Indicador 2. Respeta las ideas de los demás, sus orígenes y reconoce sus contribuciones.

Indicador 3. Colabora con otros, personalmente y a través de las tecnologías, para identificar problemas de la

información y buscar sus soluciones.

Indicador 4. Colabora con otros, personalmente y a través de las tecnologías, para diseñar, aplicar y evaluar

Fig. 2. Estándares de la Asociación Americana de Bibliotecarios Escolares

Scire. $7: 2$ (jul.-dic. 2001) 53-83. 
- Son aprendices competentes e independientes. Conocen sus necesidades de información y se comprometen activamente con el mundo de las ideas.

- Demuestran confianza en su capacidad para resolver problemas y saber qué información es relevante. Manejan herramientas tecnológicas para acceder a la información y comunicarla. Operan cómodamente en situaciones donde hay múltiples respuestas, y también donde no las hay. Propugnan elevados modelos para su trabajo y crean productos de calidad. Los estudiantes alfabetizados en información son flexibles, pueden adaptarse a cambios y son capaces de funcionar independientemente o en grupos.

- Saben cómo aprender porque conocen cómo está organizado el conocimiento, cómo encontrar información, y cómo utilizar la información de manera que otros pueden aprender de ellos.

Tal como las hemos descrito, las competencias que abarca la alfabetización informacional están en la base de la preparación de los individuos para la sociedad de la información. Su adquisición es algo difícil, que implica tanto a la política educativa y de información, como a los centros de enseñanza, las BUI, los bibliotecarios y los docentes. A continuación, describiremos algunas propuestas para su implantación, tanto en el sistema educativo obligatorio como en la Universidad, y en sus respectivas BUI.

\section{La formación didáctica de documentalistas y docentes para la alfabetización informacional}

En primer lugar, para que los docentes y los documentalistas enseñen habilidades de información o implanten y desarrollen este tipo de servicios deben tener ellos a su vez una preparación adecuada. Creemos que hasta ahora la alfabetización informacional no es un contenido suficientemente presente en las titulaciones universitarias de Maestro, Pedagogía, Biblioteconomía y Documentación. Por tanto, sería importante potenciar la presencia universitaria de esta materia, y a la vez realizar actuaciones de formación permanente.

\subsection{La formación de los documentalistas}

Para desarrollar buenos programas de formación de usuarios, para ayudar al aprendizaje de los estudiantes y la mejora de sus habilidades de información, los bibliotecarios y documentalistas deben preparar adecuadamente sus capacidades didácticas. Sin ello no podrán potenciar su dimensión instructiva.

En numerosas facultades universitarias americanas (2) se han introducido desde hace varios años, áreas de aprendizaje con un alto porcentaje de contenidos educativos, enfocados a la formación de bibliotecarios escolares. Del mismo modo, nos parece importante la introducción en el currículo de las Facultades de

Scire. $7: 2$ (jul.-dic. 2001) 53-83. 
Documentación de asignaturas que enseñen formación de usuarios, como se ha hecho en los últimos años, junto a otras que tratan de los servicios de bibliotecas escolares y universitarias (3).

Pero sería también interesante una formación de postgrado específica que pudieran realizar los titulados del ámbito, que les convirtiera en especialistas en habilidades en información, y tuvieran la función de gestionar en los centros educativos de Primaria y Secundaria los espacios y recursos documentales, colaborar y asesorar a otros docentes sobre fuentes bibliográficas y electrónicas, y coordinar las actividades de carácter multimedia. Y para facilitar que los profesionales en activo aprendan los aspectos pedagógicos, hay que incluir este contenido en los planes de formación permanente del personal de bibliotecas, tanto públicas como universitarias y escolares.

Así, en Francia existen varios centros que se ocupan de la formación pedagógica de bibliotecarios, denominados URFIST (Unité Régionale de Formation et de Promotion pour l'Information Scientifique et Technique) (Fig. 3), como el de Tolouse (Link-Pezet, 1999). Y en Estados Unidos, la American Library Association, creó en 1997 su Institute for Information Literacy para preparar a

\section{FORMATION DE FORMATEURS}

\section{COMPETENCES DES FORMATEURS A LA RECHERCHE DOCUMENTAIRE}

\section{Le projet FORSIC décembre 1999}

\section{DIDACTIQUE DE L'INFORMATION SCIENTIFIQUE ET TECHNIQUE}

1. Introduction à la didactique : cours, bibliographie.

2. Etude d'un cédérom : DocThèse

3. Formation et questionnement. Etude d'un cédérom : Francis

4. Analyse didactique d'une séance de formation en amphithéâtre pour des étudiants de DEA.

5. Bilan du cycle sur la didactique de l'IST.

6. Les styles cognitifs.

\section{VERS UNE STRATEGIE DE L'ACTION}

1. Les réflexions de I'URFIST sur la didactique et l'ingénierie de I'IST.

2. Exemple d'un programme de formation a l'IST pour les étudiants : Ie SCD de I'Université Paul Sabatier à Toulouse.

3. D'une pratique professionnelle à une pratique de formation : compte-rendu

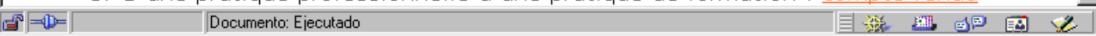

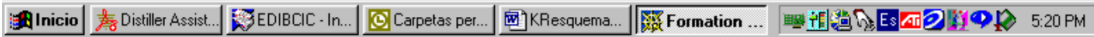

Figura 3. Página web de una Unité Régionale de Formation et de Promotion pour l'Information Scientifique et Technique

Scire. $7: 2$ (jul.-dic. 2001) 53-83. 


\begin{tabular}{|c|c|c|c|c|}
\hline ↔ " | Árchivo Édición & Yer Eavoritos & Herramientas & Ayuda & Vínculos"界 - \\
\hline & IIL Home & Site Map & IIL Organization Program Initiatives & \\
\hline $\begin{array}{l}\text { Institute for } \\
\text { Information } \\
\text { Literacy }\end{array}$ & $\begin{array}{l}\text { Other Infor } \\
\text { Progr }\end{array}$ & ation Litera & $\begin{array}{l}\text { y Resources About IIL Website ACRL Home } \\
\text { itiatives }\end{array}$ & \\
\hline
\end{tabular}

\begin{abstract}
-Institute for Information Literacy Immersion Programs
ACRL's II offers a competitive national Immersion Program each summer. The four and one-half-day Program provides instruction librarians with the intellectual tools and practical techniques to help their institutions build or enhance their instruction programs. Participation is limited to 90 to ensure an environment that fosters group interaction and active participation.

Each Immersion Program offers two tracks. Track I is designed for new librarians or instruction librarians who are interested in enhancing, refreshing, or extending their individual instruction skills and applying them to institutional programs. Track $\Pi$ is designed for instruction librarians who seek to further develop, integrate, or advance an information literacy program within their institutions. A faculty of nationally recognized librarians and scholars teach the Programs.

Detailed application information for upcoming national Immersion Programs will be posted on the III Web site in September of the year prior to the date of the Program. Required application materials will include a one-page resume, two letters of reference, a completed cover form, and a two-page (Track I) or three-page (Track II) application statement.
\end{abstract}

los bibliotecarios para la alfabetización informacional y difundir las mejores prácticas que se pueden utilizar para conseguirla.

El Institute for Information Literacy (Fig. 4) surgió (Oberman, 1998) porque en el entorno bibliotecario americano la demanda de programas de alfabetización informacional y de enseñanza de los procesos bibliotecarios venía creciendo exponencialmente desde los años setenta, y era todavía poco reconocida como componente fundamental de la formación de los bibliotecarios. Conforme la Educación Superior se iba orientando hacia la comprensión de la información, se veía la necesidad de un organismo dedicado:

- A preparar bibliotecarios para ser enseñantes efectivos de los programas de alfabetización informacional.

- Al apoyo a los bibliotecarios, a otros docentes y a los gestores universitarios para ejercer el liderazgo en el desarrollo e implantación de los programas de alfabetización de la información.

- A forjar nuevas relaciones con toda la comunidad educativa para trabajar en el desarrollo del curriculo de la alfabetización informacional. 
- A dar oportunidades para el crecimiento y desarrollo en el ámbito cambiante de la alfabetización informacional.

Los programas del Institute for Information Literacy son tres:

- Programa de inmersión: Se imparten cursos intensivos del tema, a dos niveles, uno para bibliotecarios que se estén iniciando y otro para profesionales que vayan a liderar la alfabetización informacional en sus instituciones. En el URL http://www.ala.org/acrl/nili/outcomes.html se describen sus objetivos: capacitar en alfabetización informacional, enseñar a liderar los procesos educativos en el entorno universitario, conocer las teorías del aprendizaje y los métodos de enseñanza, y enseñar la evaluación y gestión de cursos.

- Programa de prácticas ejemplares: Dirigido a ayudar a las instituciones a desarrollar estrategias para la creación e implantación efectiva de programas de alfabetización informacional, proporcionando criterios de evaluación, identificando programas modelo que ilustren estos criterios, y divulgando información sobre criterios y modelos para su docencia en la enseñanza superior.

- Colaboración: Iniciativa para promover el diálogo para la alfabetización informacional en todo el espectro educativo.

\subsection{La formación del profesorado}

Son también necesarias actividades de formación en el campo de los docentes, tanto en las facultades de Educación como a través de la formación permanente, para que puedan incorporar estas nuevas demandas de aprendizaje. Para ello hay que realizar actividades de formación, presenciales y/o a distancia, organizadas por Centros de Profesores, Universidades o Instituciones culturales avaladas por las administraciones educativas. Se debe fomentar la sensibilización y preparación de los docentes en estos temas, de modo que tengan en cuenta que acercar la sociedad de la información es mucho más que poner ordenadores en los centros educativos. Ello implica una remodelación de los contenidos, de la metodología didáctica y de los escenarios de aprendizaje.

El Ministerio de Educación y Cultura y las administraciones educativas autonómica organizan cursos para profesores sobre bibliotecas escolares, incluyendo contenidos sobre sus servicios. Se quiere destacar una experiencia expresamente realizada sobre alfabetización informacional realizada desde el CEFIRE de Elche por uno de los autores, Benito Morales. Se trató de un curso a distancia por Internet denominado "Educación Documental: una nueva enseñanza transversal para alfabetizar en información" dirigido a docentes de Primaria y ESO de toda la Comunidad Valenciana. Dicha actividad de formación permanente, que fue seguida y evaluada por expertos externos, permitió señalar unas pautas para el

Scire. $7: 2$ (jul.-dic. 2001) 53-83. 
desarrollo de experiencias similares que faciliten su diseño, aplicación y evaluación, en un entorno web de aprendizaje, posibilitando:

- Analizar y valorar las implicaciones educativas de la sociedad de la información, para sensibilizar a los docentes sobre las nuevas necesidades de aprendizaje y motivarles para remodelar su actuación.

- Proporcionar modelos y estrategias de enseñanza-aprendizaje para el aula y/o las áreas curriculares, de acuerdo a los principios de la educación documental.

- Realizar proyectos para la organización y dinamización de espacios de información (como la mediateca escolar) y entornos informáticos en el centro educativo.

- Facilitar recursos bibliográficos y electrónicos para continuar la formación permanente.

- Crear grupos de trabajo y seminarios permanentes (virtuales y presenciales) para facilitar la colaboración y el intercambio de ideas y recursos entre los profesores.

Dicho curso consiguió no sólo una mejora de los conocimientos de los docentes sobre el tema, sino algo más importante: un desarrollo de sus propias habilidades de información, las cuales conllevan factores cognitivos, informativo-documentales, y actitudinales, y un desarrollo de iniciativas en sus propios centros, implicando a sus compañeros, que potencien su colegio o instituto como un centro para la alfabetización informacional.

\section{Propuestas para la enseñanza de la alfabetización informacional en el Sistema Educativo Obligatorio}

\subsection{La dotación, dinamización y mejora de las bibliotecas escolares como centros de recursos multimedia}

Un primer requisito para la enseñanza de habilidades de información es la dinamización y mejora de los espacios de información en los centros educativos: rincones, bibliotecas de aula y escolares, aula de informática y aula-taller de Documentación. Este último serviría para el estudio y la elaboración de productos informativo-documentales, desarrollando al mismo tiempo procesos cognitivos y metacognitivos (solución de problemas, toma de decisiones, indagación científica y composición de textos, impresos y electrónicos). Esta propuesta implica un cambio en los procedimientos didácticos del docente, dejando atrás el libro de texto y la clase magistral como únicas fuentes de información.

Para conseguir que estos espacios de información sean factibles, las administraciones educativas deben diseñar estrategias para la dotación y gestión de recursos, así como permitir que los centros públicos adopten medidas para su

Scire. $7: 2$ (jul.-dic. 2001) 53-83. 
autofinanciación. Para ello, uno de los recursos básicos es el personal. A pesar de que en los últimos años ha aumentado el número de especialistas en los centros educativos no universitarios - hay docentes especialistas de materias como Tecnología, Música o Pedagogía Terapéutica—, las bibliotecas u otros espacios de información son organizados y dinamizados por docentes voluntariosos, que desarrollan su labor con una mínima formación y que reciben como única compensación una pequeña reducción de su horario lectivo. Se requiere consolidar esta nueva figura profesional, con el reconocimiento de los bibliotecarios escolares y la introducción en los Centros de Profesores de asesorías dedicadas al tratamiento y dinamización de la información en sus diferentes formatos.

\subsection{La Educación Documental como tema transversal}

Por su carácter metodológico y aplicable a cualquier ámbito de contenidos o área curricular, se debería introducir una nueva enseñanza transversal, la "Educación Documental", que como tal incidiera en el desarrollo de las unidades didácticas de cualquier área de aprendizaje. Recibe la denominación de "documental" debido a que su principal finalidad es la instrucción de los escolares en el acceso a la información, entendiendo por acceso la expresión de dos procesos con múltiples paralelismos: el acceso a la información que está fuera de nuestra mente y el acceso a la información que está dentro de ella. Es decir, el conocimiento como construcción cognitiva para obtener un pensamiento crítico y creativo, y un comportamiento inteligente caracterizado por un aprendizaje estratégico; y el conocimiento como información documental, para recuperar, gestionar y transferir información. La "Educación Documental" se articularía en torno a las variables de Pensamiento, Información y Valores, con la finalidad de hacer de los ciudadanos personas que sepan actuar de forma autónoma y estratégica, capaces de enfrentarse a situaciones y contextos cambiantes, preparados para aprovechar, tanto los propios recursos mentales para autorregular el aprendizaje, actuando de forma participativa y solidaria, así como las herramientas tecnológicas que facilitan la localización, procesamiento y comunicación de información. Por tanto, aprender a pensar, aprender a informarse y aprender a vivir, constituyen los aspectos básicos de esta nueva enseñanza transversal.

\subsection{La enseñanza de las habilidades de información como materia optativa en la ESO}

En la configuración de la Educación Secundaria Obligatoria se ofrece a todos los alumnos la posibilidad de realizar optativas, con las que no se pretende profundizar o reforzar los contenidos de las áreas básicas, sino:

- Facilitar aprendizajes globalizados y funcionales.

- Facilitar la transición a la vida activa y adulta. 
- Ampliar la oferta educativa y las posibilidades de orientación dentro de ella.

La implantación de materias optativas relacionadas con la alfabetización informacional es muy reducida, pues, por un lado, los docentes no están formados para impartirlas y, por tanto, no se ofertan al alumnado; por otro, los alumnos no las demandan porque desconocen sus contenidos y posibilidades. Y además los recursos documentales disponibles son escasos. Sin embargo, actualmente se imparten en distintas comunidades autónomas materias optativas relacionadas con las habilidades de información, entre las que cabe mencionar las siguientes:

- Procesos de Comunicación (en el ámbito gestionado por el MEC)

- Técnicas de Documentación y Tratamiento de la Información (I. E. S. Fray Luis de León, Salamanca), elaborada por sus profesores a partir de la anterior.

- Información y Comunicación (Andalucía)

- Metodología Documental (Valencia)

- Información Documental y Aprendizaje (País Vasco)

\subsection{La implicación de docentes con bibliotecarios y otros especialistas en información y documentación, y con sus respectivas instituciones}

Esta colaboración es posible de muchas formas: tanto a través del apoyo de las bibliotecas públicas en el desarrollo de actividades educativas, como formando equipos multidisciplinares de investigación sobre educación documental (EMIED), para realizar el diseño, la aplicación y la evaluación de módulos de aprendizaje, referidos a objetivos generales y contenidos de las áreas curriculares, con la finalidad de que los escolares mejoren la ejecución de tareas intelectuales, adquieran las bases de una formación humanística y técnica centrada en el mundo de la información, e incrementen sus hábitos y estrategias para una eficaz formación permanente. La apertura de la escuela a la sociedad de la información, exige la apertura a las ideas y experiencias de otros profesionales como los bibliotecarios.

\subsection{Hacer de la enseñanza de habilidades de información un elemento básico para la atención a la diversidad}

La biblioteca escolar presenta, como centro de información y de recursos, múltiples perspectivas del conocimiento que facilitan la conexión entre las diferentes disciplinas, consiguen una visión más coherente y más integrada del saber, y fomentan el desarrollo de valores positivos relacionados con la cultura y el pensamiento, siendo un entorno ideal para conjugar el humanismo y la tecnología. Permite seleccionar textos de acuerdo al nivel madurativo lectoescritor, y a los intereses y preocupaciones de cada escolar. Y además es una herramienta básica para conseguir el derecho de los escolares en pro de la igualdad de oportunidades y de la igualdad en el acceso a la información.

Scire. $7: 2$ (jul.-dic. 2001) 53-83. 


\subsection{Considerar la enseñanza de habilidades de información un indicador de calidad del sistema educativo no universitario}

Aprender a aprender ha sido citado por la Comisión Europea como uno de los indicadores clave para ayudar a la evaluación nacional de sistemas en el área de estándares escolares, porque implica el desarrollo de un grupo generalizado de herramientas y habilidades que apoyan el proceso de aprendizaje en muchos contextos diferentes. La importancia de las habilidades que capacitan a una persona para sobrevivir en el complejo mundo del trabajo y tomar ventaja de las nuevas oportunidades ha aumentado. La rapidez y complejidad de los cambios demanda una conexión estrecha entre educación escolar y educación permanente, mediante el desarrollo de habilidades de información. Dentro de una cultura de la mejora permanente, en la autoevaluación de un centro educativo, se deben implementar todos los aspectos posibles referidos a las habilidades de información en los criterios ya establecidos por el Modelo EFQM (European Foundation for Quality Management): liderazgo, planificación y estrategias, gestión, recursos, procesos, satisfacción del cliente/usuario, satisfacción del personal, impacto en la sociedad y resultados del centro educativo.

\subsection{Fomentar la investigación y la publicación en el campo de las habilidades de información}

Para el fomento de la investigación en el campo de las habilidades de información debería incluirse, como tema prioritario dentro de las convocatorias de ayudas a proyectos de innovación educativa. De entre las posibles temáticas de investigación, podemos destacar las cinco siguientes:

- Sociológica: Dirigida al estudio de su repercusión y alcance social, los proyectos e inversiones de organizaciones locales, nacionales e internacionales, y las relaciones de colaboración del mundo educativo con el bibliotecario.

- Histórica: Centrada en los hechos y testimonios que inciden en su desarrollo, tanto en el marco legal y administrativo, como los encuentros, manifiestos y publicaciones referidas a las habilidades de información.

- Epistemológica: Dirigida a fundamentar el marco teórico, mediante el desarrollo conceptual y el diseño de modelos, que oriente la práctica educativa, justificando el porqué y el para qué de las habilidades de información.

- Aprendizaje: Basada en el desarrollo y validación de programas tanto para que los escolares adquieran estrategias de acceso a la información, como para que los docentes aprovechen los servicios y materiales en su trabajo docente.

- Gestión y dinamización: Dedicada a establecer la participación y las tareas de las personas y equipos implicados, y a desarrollar y validar estrategias para motivar el interés y la participación de los escolares. 
El resultado debe ser la difusión de publicaciones, impresas y electrónicas que expongan modelos, experiencias y actividades que puedan desarrollar docentes y profesionales de las BUI. Numerosas universidades y asociaciones americanas, disponen de páginas web dedicadas a ofrecer información de sus programas e iniciativas para el desarrollo de habilidades de información, y los artículos recogidos en LISA sobre el tema son casi 300 desde 1991, con un incremento constante (4).

\section{Propuestas para la enseñanza de la alfabetización informacional en la Universidad}

De modo muy rápido se están extendiendo las habilidades electrónicas entre los universitarios. Las universidades están haciendo evaluación de sus titulaciones y servicios, y desarrollando planes estratégicos, como "Paidea", de los que se derivan nuevas posibilidades para la imbricación de docentes y bibliotecarios de cara a mejorar la capacidad de información y autoaprendizaje de los estudiantes. En algunos casos se está abriendo la posibilidad de asignaturas de libre configuración impartidas por los bibliotecarios; la sencillez de los interfaces aumenta; crecen las tecnologías disponibles para los universitarios a través de múltiples salas de ordenadores en red, y está casi universalizado el acceso a correo electrónico de los estudiantes. Las redes telemáticas van a transformar la enseñanza universitaria y conviene por ello que alumnos, profesionales de las BUI y docentes se adapten y aprendan nuevas habilidades.

\subsection{Introducir la alfabetización informacional como contenido de aprendiza- je y evaluación dentro de las distintas asignaturas de los planes de estudio}

Las habilidades de información tienen un carácter metodológico y transversal, en tanto podemos considerarlas necesarias para el dominio de cualquier materia. Por ello, de modo ideal, la alfabetización informacional debería ser resultado del empleo de métodos didácticos que implicaran su conocimiento y uso en el seno de todas las asignaturas. La alfabetización informacional en el seno de todas las asignaturas llevaría al aprendizaje "en contexto" de las habilidades de información, lo cual es altamente positivo y coherente (Berhnard, 1998, Oker-Blom, 1998 ; Rader, 1999b ; Stein, 1998 ; SCONUL, 1999). Es positivo porque la motivación para las tareas de aprendizaje es más fácil cuando el acceso y uso de la información se lleva a cabo no en abstracto o en general, sino con un objetivo y una temática que es parte de los contenidos en los que el estudiante está formándose. Y es coherente porque en todas las disciplinas o asignaturas concretas hay dificultades para conocer los recursos, las características propias de la documentación especializada de ese campo, unos hábitos propios de comunicación y publicación. 
Algunos estudios (Oker-Blom, 1998; Barry, 1999) han comprobado que los profesores universitarios tienen escasa práctica en la enseñanza de habilidades de información, considerando que su aprendizaje por los alumnos puede ser autodidacta, durante el proceso de realización de trabajos académicos. Asumen que simplemente haciendo ir a los estudiantes a investigar un problema en la biblioteca aprenderán espontáneamente las habilidades de información. Además, está comprobado que el alumno atiende básicamente a los contenidos estrictamente curriculares que se le evalúan, es decir, intenta responder a las demandas de la educación formal que determinan el éxito en sus calificaciones. La motivación extrínseca más elemental para el alumnado es la evaluación. De modo que si los profesores utilizan métodos didácticos que impliquen el dominio de las habilidades de información y evalúan la adquisición de estas competencias como hacen con el resto de aspectos de sus asignaturas, aseguraremos el interés, el esfuerzo y la práctica para su adquisición.

El profesorado y los bibliotecarios (ACRL/ALA, 2000a) deberían colaborar en el desarrollo de instrumentos y estrategias de evaluación en el contexto de las asignaturas específicas, puesto que las aptitudes para el acceso y uso de la información siempre se manifiestan en la comprensión específica de la creación de conocimiento y los procesos propios de cada disciplina.

El profesor debe ser ejemplo para el alumno de actualización y de rigor, debe incluir entre las prácticas de la asignatura actividades documentales, y debe supervisarlas, corregirlas y valorarlas. No solo debe citar de modo cosmético bibliografía; debe ir guiando, ilustrando, proponiendo y revisando el proceso de aprender a informarse del alumno.

Otro aspecto muy importante para la alfabetización informacional es, tras revisar los conocimientos previos de los contenidos a tratar, el aprendizaje del proceso intelectual de decidir, delimitar, perfilar y reorientar las necesidades de información y los objetivos de las búsquedas. Para ello, el profesor tiene que acompañar a los alumnos en el proceso de comprender un campo del conocimiento, sus problemas y posibilidades. Aquí, la observación, la interrogación y la dialéctica con el profesor en el aprendizaje de la asignatura son las técnicas didácticas más importante, junto a la realización de búsquedas exploratorias y análisis de reviews. También requiere la orientación del profesor y el diálogo en la fase de análisis y valoración crítica de la información obtenida, así como la elaboración de conclusiones, la aplicación y la redacción de textos personales derivados del trabajo elaborado. Desde el punto de vista de la biblioteca universitaria, la colaboración puede darse en todos los niveles, pero especialmente habrá que ayudar a los docentes con buenos recursos documentales, facilitando el trabajo del alumnado en las bibliotecas y ayudarles a superar sus dificultades en los trabajos académicos, pero sin resolverlas por ellos.

Scire. $7: 2$ (jul.-dic. 2001) 53-83. 


\subsection{Ofertar asignaturas optativas y cursos de libre configuración de docu- mentación especializada en los planes de estudio universitarios}

Dentro de la estructura académica, otra posibilidad de alfabetización informacional es la inclusión en los Planes de Estudio de asignaturas de introducción a la documentación especializada en las distintas carreras y temáticas. Estas asignaturas están muy extendidas, principalmente en universidades francesas (5), canadienses y anglosajonas, siendo su efecto una mejora del rendimiento de los alumnos (Holzem, 1995). En España, en cambio, son relativamente escasas, si bien va habiendo algunos ejemplos significativos. Desde fines de los años ochenta y principios de los noventa, con el proceso de reforma de planes de estudio, se fueron incorporando asignaturas de documentación especializada, sin contar las de las carreras de Documentación y Periodismo, en algunas titulaciones del ámbito de las ciencias de la salud (Medicina, Enfermería), la Química (Licenciado en Química, Licenciado en Bioquímica), Gestión y Administración Pública, o Humanidades (Geografía e Historia), casi siempre optativas. Pero la presencia de asignaturas de introducción a la documentación especializada equiparables a alfabetización informacional debemos considerarla reducida, frente a su relativa abundancia en el doctorado (Gómez Hernández, 1996b), lo que reflejaría la ausencia previa, y la relación conceptual en la enseñanza universitaria de la alfabetización informacional con la tardía necesidad motivada por la investigación para la tesis (6).

Una manera alternativa de acercar los contenidos que pretendemos enseñar a la estructura académica es que tanto el Área de Biblioteconomía y Documentación como los bibliotecarios programen cursos o asignaturas destinados a ser elegidas por los alumnos como parte de sus créditos de libre configuración. Aunque se ha producido una desvirtuación de la finalidad para la que se incluyeron este tipo de créditos en los planes de estudio, si los estudiantes pueden aprovechar para su currículo los cursos de formación de usuarios que programan las bibliotecas, los realizarán en mayor cantidad y con mayor interés. Como ejemplo de cursos con valor para libre configuración tenemos los de "Introducción a la Biblioteca" (Merino y Rufi, 2000), "Recuperación de Información en Bases de Datos, Recursos de Información y Gestión de Registros Bibliográficos" de la Politécnica de Valencia (http://www.upv.es/ bib/adc/adc0htm), así como diversas asignaturas y cursos de Documentación Especializada impartidos por profesorado del Área de Biblioteconomía y Documentación (7).

\section{3. Utilizar los trabajos académicos y los proyectos de fin de carrera como oportunidad para la alfabetización informacional}

En la enseñanza universitaria el trabajo individual es una oportunidad para que el alumno culmine su formación, compruebe su avance, aprenda a informarse

Scire. $7: 2$ (jul.-dic. 2001) 53-83. 
y a investigar, preparándose para transferir lo aprendido a un problema de investigación nuevo. Los trabajos pueden formar parte de los contenidos de una o varias asignaturas interrelacionadas, plantearse a la conclusión de los Estudios, como una asignatura más, denominable "Proyecto Fin de Carrera", o bien constituir un requisito obligatorio adicional, como ocurre en las titulaciones de Ingeniería.

Como contenido de cualquier tipo de asignatura, su viabilidad exige coordinación entre los profesores que los programan, pues para realizarlos hace falta tiempo fuera del aula, y eso los hace difíciles, especialmente cuando se acumulan en varias asignaturas, o cuando el horario está ocupado por las prácticas de cada una de ellas. Para nosotros sería conveniente que se programaran estos trabajos de modo conjunto entre varias asignaturas, lo que reduciría su número, facilitando una profundización mayor y una buena integración de las diversas materias.

Las experiencias de apoyo desde las bibliotecas a estos trabajos van desde la facilitación de los materiales y la orientación en las búsquedas documentales que implican, hasta la enseñanza del uso de las bases de datos de modo individualizado o la colaboración en cursos de doctorado de tipo metodológico. Un esquema de la colaboración de docentes y bibliotecarios para enseñar el proceso de investigación mediante la realización de un proyecto o trabajo durante un semestre podría ser el siguiente (Stein y Lamb, 1998):

- Reunión de intercambio de ideas entre profesor y bibliotecario para abordar el trabajo.

- Sesión de clase: el profesor plantea el proyecto, plantea posibles temas, da esquemas de referencia para su elaboración.

- Sesión en la biblioteca: el bibliotecario explica las fuentes de información y se realizan demostraciones prácticas con fuentes impresas y electrónicas

- Actividad independiente del alumno: El alumno recoge bibliografía, evalúa la utilidad de cada referencia y va refinando sus propias ideas

- Propuestas de proyectos: El estudiante debe aportar los conceptos que abarca su propuesta, palabras clave que ha usado en sus búsquedas, revisión de literatura relacionada con el tema, cuestión principal que abordará en su trabajo, objetivos y metodología que piensa adoptar.

- Revisión de propuestas: Los alumnos revisan sus propuestas teniendo en cuenta las sugerencias recibidas del profesor y la ayuda del bibliotecario.

- Realización del proyecto: Los alumnos trabajan en la obtención de datos y en redacción del informe de investigación.

- Reunión final: Bibliotecario y profesor revisar los resultados.

Entre los ejemplos de colaboración de la biblioteca en los trabajos tenemos el de la Universidad Politécnica de Cataluña, que imparte sesiones de formación para

Scire. $7: 2$ (jul.-dic. 2001) 53-83. 
estudiantes matriculados en el Proyecto Fin de Carrera para enseñarles prácticamente a conocer y enseñar a usar los recursos de interés, incluyendo bases de datos, patentes, etcétera. Finalmente, una colaboración adicional es hacerlos disponibles de modo electrónico a través del sitio web de la Biblioteca (Merino y Rufi, 2000), tanto por su contenido informativo como por ser modelo para otros trabajos.

\subsection{Realizar acciones de potenciación y adaptación de la formación de usuarios de acuerdo a las nuevas necesidades de aprendizaje}

Para que la formación de usuarios alcance un protagonismo coherente con las demandas educativas de la sociedad digital que hemos explicado debemos lograr la asunción conceptual por parte de todos los docentes, gestores y bibliotecarios de la función educadora de la biblioteca universitaria, y formalizar un compromiso con la enseñanza del acceso y uso de la información. Hay que evitar que pueda considerarse ocasional o secundaria respecto a otros servicios (8).

- Una primera medida es procurar la inclusión en las normas sobre servicios bibliotecarios. Desde 1997 REBIUN ya cita como servicio la formación de usuarios, con un nivel básico y otro más amplio al que da carácter optativo. Y también en un apartado sobre "Facilidades para el estudio, tecnología para el aprendizaje e investigación" se denota un compromiso con la función educativa de la biblioteca universitaria, los estilos de aprendizaje, y la disposición de recursos telemáticos y espacios de autoaprendizaje. Igualmente se recoge este aspecto en las recientes Normas para Bibliotecas Universitarias de pregrado (ACRL/ALA, 1999), y sobre todo son importantes las recientes Normas sobre aptitudes para el acceso y uso de la información en la Enseñanza Superior (ACRL/ALA 2000a), qué explican cuales son las habilidades de información necesarias en el sistema educativo, y formulan cinco estándares, relativos al dominio de las distintas competencias, y sugieren indicadores y resultados observables de su consecución (9).

- Recoger explícitamente este servicio dentro de carta de derechos de los usuarios, como ha hecho la Autónoma de Barcelona, la primera biblioteca universitaria que ha obtenido el Certificado de Calidad de acuerdo a la ISO 9002 (http://www.bib.uab.es/avaluacio/carta.htm):

8. Formació d'usuaris: Les biblioteques de la UAB ofereixen cursos per tal que els seus usuaris obtinguin els coneixements necessaris per a treure el màxim de profit dels recursos documentals i serveis (...). L'usuari pot demanar informació als taulells d'informació o taulells de préstec de les biblioteques de la UAB. S'organitzen cursos generals i introductoris (com consultar eficaçment el catàleg informatitzat, saber com està organitzada una biblioteca), cursos especialitzats o monogràfics propis de cada biblioteca (com trobar recursos sobre una determinada matèria, funcionament de bases de dades locals i en xarxa) i, en alguns casos, cursos ala carta, a partir de les necessitats de grups determinats d'usuaris.

Scire. $7: 2$ (jul.-dic. 2001) 53-83. 
- Incluir un departamento o sección para este servicio en la estructura de la plantilla de las bibliotecas, o dentro de otras áreas como referencia.

- Destacar esta misión dentro del plan estratégico de la biblioteca: Así, por ejemplo, el programa Escher, puesto en marcha por la Biblioteca de la Universidad Politécnica de Cataluña en 1995, definía la biblioteca como un lugar para aprender a aprender, y se marcaba entre otros objetivos hacer de la biblioteca un lugar de autoformación, favorecer el trabajo intelectual y el uso de los recursos (10). Estos objetivos se han visto aún más impulsados por el nuevo programa 2000-2005, el ya citado "Paideia", en el cual la biblioteca asume entre sus principales aspiraciones a favor del aprendizaje el educar a los usuarios en habilidades y capacidades para aprender constantemente a vivir en un mundo global y hacer de las bibliotecas espacios en los que los nuevos roles del profesor y el alumno puedan crecer en torno a la información y el aprendizaje. De esta concepción se deriva la formación de usuarios y la potenciación de áreas de autoaprendizaje: espacios equipados con los recursos informáticos adecuados para el aprendizaje autónomo de habilidades y capacidades, incluyendo ofimática, idiomas, técnicas de investigación, Internet, etc.

- La evaluación y la gestión de calidad como herramientas que están llevando la atención hacia la importancia de la formación de usuarios, según confirman las evaluaciones realizadas por las bibliotecas universitarias en los últimos años, como en la Universidad de Salamanca, y en las de Cataluña, donde aparece este servicio dentro de las propuestas de mejora.

\section{5. Realizar regularmente de experiencias de formación de usuarios en bibliotecas universitarias}

Una manera básica de enseñar a los usuarios han sido las visitas guiadas, los cursos introductorios y luego otros de profundización. Están presentes en muchas bibliotecas universitarias, y un ejemplo pueden ser los de la Autónoma de Barcelona: Conèixer les Biblioteques (http://www.bib.uab.es/ formacio/curs.htm), o el que nos parece más completo, el de la Biblioteca de la Universidad Politécnica de Cataluña, que incluye, bajo el programa "Como trobar i gestionar informació científico-técnica”, sesiones de formación generales, temáticas o especializadas, y otras vinculadas a los estudios de la UPC, con orientaciones para la realización de los proyectos fin de carrera (http://escher.upc.es/STS/formacio/inici.htm). Además de formación reglada, los bibliotecarios deben dar una formación individualizada o concertada con pequeños grupos. Para ello se debe reservar una franja en el horario de apertura de la biblioteca, en el caso de la formación individualizada, y acordar citas con los grupos. 


\subsection{Incluir la formación de usuarios y aspectos de alfabetización informacional en el portal web de las bibliotecas}

La utilización de la página web de la biblioteca para la formación de los usuarios y la alfabetización informacional se puede hacer de varias maneras:

- Mediante programas de orientación y apoyo del aprendizaje y la docencia. Un buen ejermplo es la biblioteca de la Universidad Politécnica de Cataluña, que proprociona información básica, tanto de modo impreso como a través de Accés, su sistema de información. Además, la propia biblioteca tiene un área con recursos tecnológicos para el autoaprendizaje, que facilita recursos, software, tecnología, etc.

- Mediante el desarrollo de bibliotecas digitales con los recursos didácticos de apoyo de las asignaturas: apuntes y bibliografía recomendada (10). Es una manera de llevar la biblioteca al aula, de estrechar el vínculo de docencia y recursos de información, y ello se refleja en las denominaciones de los proyectos bajo los cuales se desarrollan: Estantería Virtual en el caso de la Universitat Oberta de Catalunya (Soler, 2000) o Campus Global en la Pompeu Fabra (Esparó, 2000). Este llevar la biblioteca al aula permite

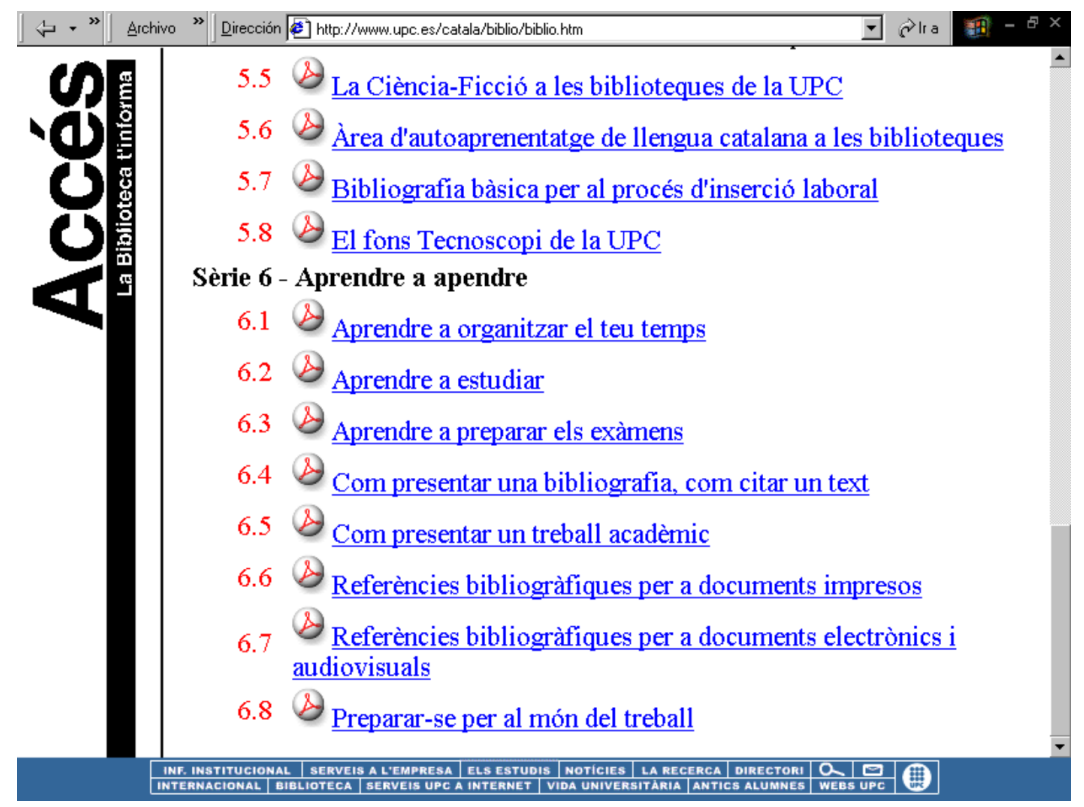

Figura 5. Biblioteca digital de la UOC

Scire. $7: 2$ (jul.-dic. 2001) 53-83. 
(Sangrá, 2000) un acceso rápido a la información, que se puede filtrar y tratar, incrementando la facilidad de consulta de las fuentes y la interdisciplinariedad. Mantienen y dan acceso a la bibliografía recomendada con enlaces, textos-guía de los profesores, acceso a la biblioteca, a su catálogo y bases de datos, así como a otros recursos web, como exámenes de otros años, colecciones de problemas resueltos, artículos complementarios a texto completo, textos legales, ejercicios de autoevaluación, dossieres, esquemas, programas teóricos y de prácticas. En algún caso se proporcionan manuales específicos sobre el uso de fuente de información, que forman parte de los materiales didácticos de algunas asignaturas, por ejemplo de las de Multimedia y Comunicación o Introducción al Derecho (Pérez, 2000) (12) (Fig. 5, en la página anterior).

- Formación de usuarios mediante guías electrónicas de las bibliotecas, sus bases de datos y catálogos, y tutoriales hipertexto en formato electrónico. La formación en el entorno telemático está adquiriendo un protagonismo cada día mayor. Los sitios web proporcionan las guías de uso de las bibliotecas, la explicación de los recursos documentales y las estrategias de búsqueda, así como respuestas a las cuestiones más frecuentemente planteadas por los estudiantes (FAQs). Quizás todavía se observa a veces un volcado excesivamente lineal de las explicaciones impresas del uso de los recursos, más que la preparación de documentos hipertextuales e interactivos que favorezcan la participación y autoevaluación de la comprensión mediante ejemplos o preguntas que guíen al usuario. Pero, por encima de ello, las bibliotecas universitarias están trasladando a la biblioteca digital uno de los servicios básicos, como es la enseñanza del acceso y uso de la información. Partiendo de las guías de uso, suelen enlazar a tutoriales de uso de los catálogos y las bases de datos disponibles. Como ejemplo citaríamos la guía de uso de la biblioteca Carlos III de Madrid, por su esfuerzo por el diseño gráfico, desarrollado a través del proyecto ICARO (Malo 2000), y por la amplitud de la formación que incluye.

En los sitios web para formación de usuarios (Fig 6 y 7) es fundamental recoger la información para el uso de la biblioteca: tutoriales de los procesos de busca y recuperación de información en todos los recursos y bases de datos documentales accesibles desde la biblioteca, con referencia a operadores, estrategias de búsqueda y uso de índices; ejemplos interactivos de búsquedas que dirijan y requieran la participación del usuario; y, finalmente, ejercicios prácticos de búsqueda que obliguen a aplicar los procedimientos explicados y que permitan autoevaluar el aprendizaje (De la Mano y Moro, 1998). En cuanto al diseño, además de una accesibilidad total -incluyendo a personas con problemas perceptivos (13) — , debemos fomentar una consulta sencilla, clara, con ayudas contextuali- 


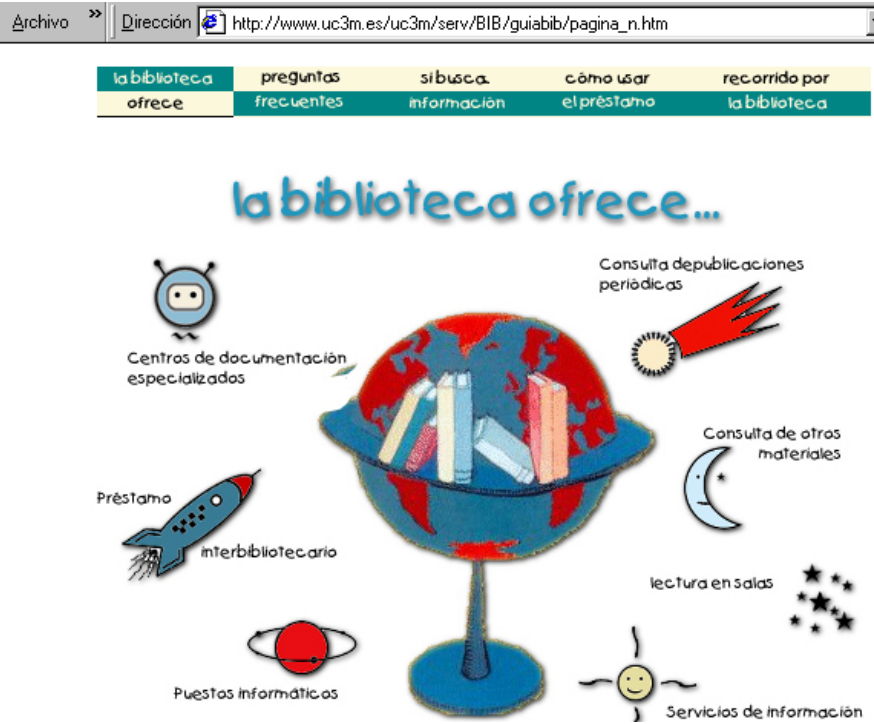

Figura 6. Ejemplo de sitio web para formación de usuarios

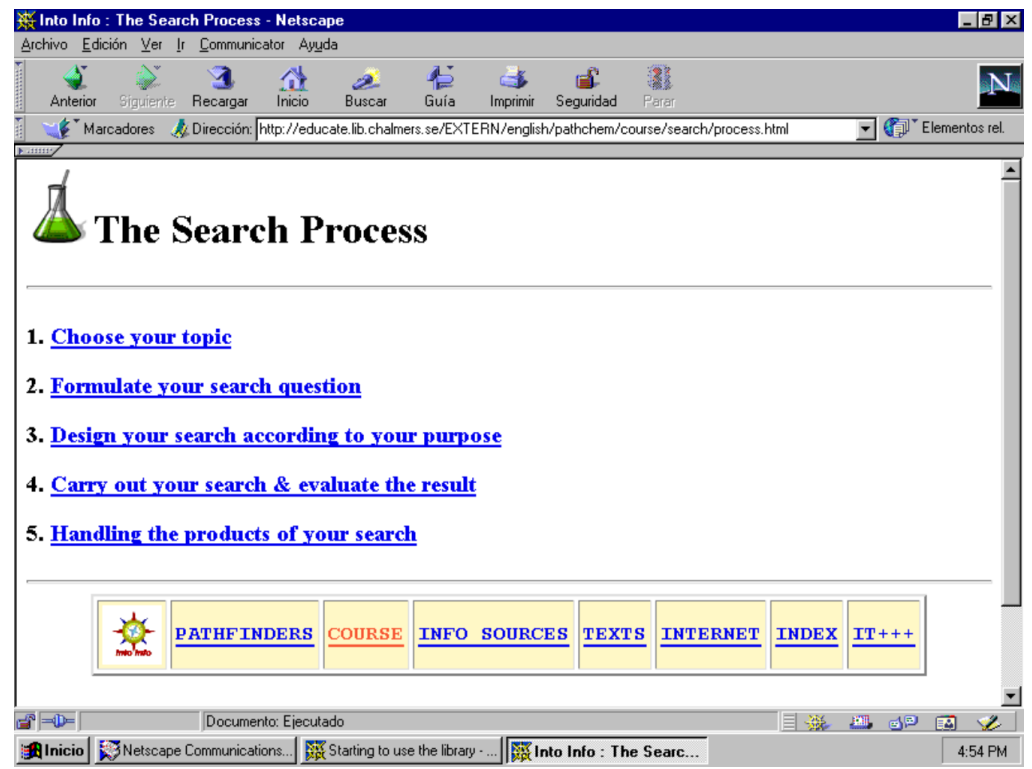

Figura 7. Ejemplo de sitio web para formación de usuarios

Scire. $7: 2$ (jul.-dic. 2001) 53-83. 
zadas en sus distintas partes, un índice o mapa del documento que permita la orientación, una representación iconográfica que favorezca el acceso visual a los contenidos, y coherencia con las características de un documento hipertexto (Rovira, 1999) (14).

\section{Reflexiones finales}

Tanto por la complejidad de la información como por la diversidad de sus fuentes, es necesario que todos los individuos aprendan un conjunto de habilidades de información, fundamentales para aprender a aprender en la sociedad de la información. Esto implica enseñar a pensar a los usuarios como parte del proceso de enseñarles a aprender y a informarse. Aprender es incorporar información nueva integrándola con nuestros conocimientos previos de modo significativo. Ello exige ser consciente del propio proceso de pensamiento (metacognición), controlar las dificultades de aprendizaje, saber delimitar las necesidades de información, saber obtener información, saber valorarla y aplicarla, y saber comunicar la información obtenida.

Esto obliga a remodelar ciertas pausas instructivas en el sistema educativo y también en las BUI, porque se necesita y es posible una mayor autonomía en el aprendizaje de los alumnos, hay nuevos medios de acceso al conocimiento, y entornos donde se valora y se debe aprender el trabajo cooperativo. Para que los estudiantes estén preparados para aprender a aprender y puedan aprender a pensar, los docentes y los bibliotecarios tenemos que cooperar en la organización de la enseñanza de las habilidades de información.

Además de recursos y condiciones adecuadas, los formadores — bibliotecarios o profesores - debemos saber conectar con las experiencias y con los conocimientos cotidianos del alumno y desarrollar un papel de orientadores. El alumno debe ser considerado con un potencial importante para construir el conocimiento, apreciando sus aportaciones y sus errores, fomentando el trabajo cooperativo, los métodos de descubrimiento y la motivación intrínseca. En sus estudios universitarios y como usuarios de bibliotecas convencionales y digitales, debemos estimularles y exigirles, y a la vez hacerles más autodidactas, más responsables de su aprendizaje, reforzando nuestra relación con ellos con medios complementarios como el apoyo de las redes de información. Para ello, los mediadores en los procesos de aprendizaje deben formarse para implicarse en un modelo educativo coherente con las demandas instructivas de la sociedad de la información.

Igual que los bibliotecarios, también el profesorado universitario debería tener una preparación específica como docente, conocer los procedimientos de aprendizaje, saber aplicar estrategias didácticas adecuadas. Se debería fomentar desde los Departamentos la reflexión sobre la enseñanza, para analizar y recons- 
truir la práctica docente. Ello ayudaría a una buena distribución de objetivos y contenidos, la coordinación de los aprendizajes, la mejora de los procesos de evaluación y la creación de un contexto en el cual los estudiantes realmente dejen de tener como referente de su enseñanza la memorización para un examen, y se capaciten para aprender durante toda la vida.

\section{Notas}

(1) En francés se habla de control o dominio de la información. En inglés, términos relacionados pero de menos alcance son "document skills", "media literacy", "computer literacy" o "information skills" (Smith, 2000). La alfabetización informacional es algo más, aunque lo incluye, que el dominio de los medios y procedimientos informáticos de acceso a la información. Por eso preferimos esta expresión a la de "alfabetización electrónica" o "alfabetización tecnológica", que también se usa en publicaciones o congresos del tema. como, por ejemplo, en el Congreso Internacional Retos de la alfabetización tecnológica en un mundo en red (http://www.juntaex.es/consejerias/ect/congreso/) organizado por la Dirección General para la Sociedad de la información de la Junta de Extremadura.

(2) Ver, por ejemplo, los programas desarrollados en Berkeley o la San José State University, como el de D. Loertscher: http://witloof.sjsu.edu/courses/250.loertscher/loer250home.html.

(3) Las hay en las Facultades de Documentación de Barcelona (Planes de Formación de usuarios), Carlos III (Evaluación de servicios y formación de usuarios), Extremadura (Bibliotecas Escolares), Granada (Bibliotecas de Centros de Enseñanza), La Coruña (Animación a la Lectura, Bibliotecas Escolares), Salamanca (Formación de Usuarios, Bibliotecas Escolares, Bibliotecas Universitarias) y Murcia, donde además de Biblioteconomía y Documentación Educativa, se imparte en la Licenciatura Habilidades y Estrategias de Información (http://www.um.es/fccd/ programlic99/hei.pdf)

(4) En España la publicación es escasa, pudiendo citarse el dossier de Educación y Biblioteca publicado en el número 92, de 1998, nuestra reciente publicación (Gómez Hernández, 2000), y varios documentos difundidos por la Revista de la Asociación Andaluza de Bibliotecarios (ACRL/ALA, 2000a) o en las undécimas Jornadas de esta asociación (Pasadas, 2000).

(5) El directorio francés de estas asignaturas (Cónference des Grandes Écoles, Index des formations à l'usage de l'information dans les universités et les grandes écoles françaises en el URL http://www.cri.ensmp.fr/cge/IST/) describe 114 asignaturas, el $75 \%$ obligatorias y el 25\% optativas. En un 37\% de los casos son dadas por bibliotecarios, en un $41,5 \%$ por equipos de docentes y bibliotecarios y en un $21,5 \%$ por docentes de las especialidades de las carreras en las que se imparten (BretelleDesmazieres, 1998). Respecto a las bibliotecas universitarias, una reciente encuesta en Francia (Noel, 1999) realizada a trescientas bibliotecas universitarias identificó un total de 338 actuaciones de formación.

Scire. $7: 2$ (jul.-dic. 2001) 53-83. 
(6) En la segunda mitad de los noventa ha ido aumentando el número de asignaturas de introducción a la documentación. Olvera y García Caro (2000), revisando los planes de estudio de las universidades en las que se imparte alguna titulación con troncalidad del área de Biblioteconomía y Documentación, han encontrado que de las 64 Universidades que existen actualmente en España, 48 públicas y 16 privadas, en el $70,83 \%$ de las primeras y en el $68,75 \%$ de las segundas se enseña alguna asignatura de estas materias en alguna de sus carreras. Pero, en muchos casos, no se trata de asignaturas propiamente de documentación o fuentes de información aplicadas a fines específicos (sólo un 8\%), sino de introducción general a las técnicas documentales, la archivística o la historia del libro, entre otros temas. Entre las que vemos más cercanas a la temática de esa alfabetización información estarían algunas optativas que Olvera y Caro citan, como "Producción y Recuperación Científica” en Alicante, "Información Especializada en Medios Audiovisuales" y "Obras de referencia para el trabajo histórico" en Barcelona, "Sistemas de navegación por la información" en la Universidad Carlos III de Madrid, "Documentación para Publicidad y Relaciones Públicas" e "Introducción a la Información y documentación en Ciencia y Tecnología" en la Universidad Complutense de Madrid, "Técnicas de Trabajo y Documentación Bibliográfica" en Granada, "Fuentes Especializadas en Documentación Jurídica y Administrativa" en Murcia, y "Documentación Médica" en Murcia, y "Métodos y Técnicas documentales del trabajo científico en Enfermería", "Documentación en Química” y "Documentación en Odontología”, de Valencia.

(7) Asignaturas de este tipo se imparten, por ejemplo, en Extremadura ("Servicios de Documentación para la Empresa"), en Granada ("Documentación aplicada a la Psicología", "Documentación aplicada a las Ciencias Jurídicas", y "Fuentes de Información en Ciencias de la Salud"), y en Zaragoza ("Documentación Científica en Agronomía"). Y cursos de libre configuración ha habido en Murcia ("Documentación Aplicada al Medio Ambiente" (http://www.um.es/fccd/curso-html/curso-medioamb.htm), "Documentación Administrativa y Jurídica" (http://www.um.es/siu/congre/ fuentes/index.html), en la Universidad Politécnica de Valencia: "Iniciación a la investigación en archivos", "Metodología para la elaboración de trabajos de investigación” y "Gestión de Información Medioambiental" (http://www.cfp.upv.es/servlet/testTriptico?acronimo=00.BIBLIOC8)... De este tipo hay muchísimos ejemplos, que frecuentemente cambian de año en año.

(8) Que todavía la formación documental no es suficiente lo acreditaron estudios como el de Pérez Díaz (1996), según el cual el método de ensayo y error y las informaciones de los amigos eran los medios principales de conocer el uso del OPAC de la biblioteca.

(9) Actualmente, la ALA/ACRL, (2000b) está desarrollando los objetivos de los programas de alfabetización informacional delimitando los que corresponderían a bibliotecarios y a profesores, y los que se deberían lograr en cooperación.

(10) "El Programa vol que les biblioteques de la UPC siguin un instrument que contribueixi a donar el nou impuls que necessita la universitat, creant les condicions adequades per al treball intel-lectual, facilitant els recursos bibliogràfics apropiats i oferint serveis bibliotecaris i documentals de qualitat (...) Aspira a l'objectiu global que 
les biblioteques de la UPC facilitin les funcions discents, docents i d'investigació de la universitat com a llocs on es pugui aprendre". Hacer de la biblioteca lugar de autoformación pretende "que tots els membres de la comunitat universitària de la UPC trobin en les biblioteques l'assessorament i l'atenció, els recursos i els serveis que els permetin usarles com a aules d'autoformació. El treball a la biblioteca ha de contribuir a adquirir mètodes d'estudi i recerca que seran usats al llarg de tota la vida professional de manera que els universitaris esdevinguin uns ciutadans madurs en la societat de la informació. Aquesta finalitat implicarà formular objectius relacionats amb les línies d'actuació següents: la formació d'usuaris, formació del personal amb vista a que puguin atendre les necessitats de la universitat moderna, l'orientació dels serveis i el personal cap als usuaris, la facilitació que les biblioteques siguin una aula d'autoformació" (URL: <http://escher.upc.es/sts/plaestra/escher.htm>).

(11) El Informe Bricall (2000) resalta la necesidad de integrar las posibilidades didácticas de las tecnologías en la educación superior, y la biblioteca tiene que fomentar la disponibilidad de los recursos documentales posibilitando el acceso e interactuación sin necesidad de coincidir con los usuarios en un tiempo y lugar concretos.

(12) Otro ejemplo de estas facilidades es la Biblioteca de la Universidad de Barcelona, a través de la sección de dossieres. Núñez (2000) cita 2955 asignaturas con dossier, con un total de 6881 documentos en marzo de 2000, y un alto número de consultas

(13) Para ello consideraremos las Web Content Accessibility Guidelines 1.0, del Consorcio W3C, y base para hacer webs accesibles a personas con limitaciones funcionales (http://www.w3.org/TR/1999/WAI-WEBCONTENT-19990505/, trad. de C. Egea: http://www.accesosis.es/ carlosegea/PautasWAI.htm). Complementariamente, el Center for Applied Special Technology (CAST) ha creado Bobby (http://www.cast.org/bobby/), un programa que analiza los problemas de accesibilidad de una página web desde las normas de W3C. En el URL http://www.accesosis.es/ carlosegea/listaverificacion.htm hay una lista de criterios de verificación, así como una guía básica de recomendaciones (http://www.accesosis.es/ carlosegea /Consejosweb.htm). Un estudio de la accesibilidad actual de las páginas web de las 100 bibliotecas universitarias más consultadas (Lily y Van Flete, 1999) demostró que sólo 40 de ellas eran juzgadas accesibles por Bobby.

(14) Buenos ejemplos de diseño de tutoriales hipertextuales serían "Into Info" (Educate, 1998) y "Tonic" (University of Newcastle, 1998), que explicamos en Gómez Hernández (2000).

\section{Bibliografía}

AASL/ALA, AECT (1998). Information Power: Building Partnerships for Learning. Chicago, ALA.

ACRL/ALA (1997). Guidelines for instruction programs in academic libraries. URL=<http://www.ala.org/acrl/guides/guiis.html. [Consulta noviembre de 1999].

ACRL/ALA (1999). Normas para bibliotecas universitarias de pregrado. Edición 2000. Trad. de Cristóbal Pasadas Ureña. URL: <http://www.aab.es/033trad3.htm>. 
ACRL/ALA (2000a). Information Literacy Competency Standards for Higher Education. URL: <http://www.ala.org/acrl/ilcomstan.html>. Versión Española: Normas sobre aptitudes para el Acceso y Uso de la Información para la Educación Superior. // Boletín de la Asociación Andaluza de Bibliotecarios, 60. URL: <http://www.aab.es/ 51n60a6.pdf>.

ACRL/ALA (2000b). Objectives for Information Literacy Instruction by Academic Librarian.URL:<http://www.libraries.rutgers.edu/is/projects/objectives/ index.html>. La traducción española de Cristóbal Pasadas estará disponible en el URL: <http://www.aab.es>.

Aloguin Pallach, M. ; Duarte, G. ; Gonzalez Ugarte, J.L. (2000). Docencia, investigación, tecnología y biblioteca: la convergencia en la gestión del conocimiento. // Rebiun Seminario Barcelona : La biblioteca al servicio de la docencia y la investigación. <URL: <http://biblio.uoc.es/cas/rebiun/jornada.htm>. Consulta: mayo de 2000.

Bargalló, M. T. ; et. al (1999). La biblioteca universtària davant del repte de les noves formes d'aprenentatge. // 7es Jornades Catalanes de Documentació. URL: <http://www.cobdc.org/7es/59.pdf>.

Barry, C. A. (1999). Las habilidades de información en un mundo electrónico: la formación investigadora de los estudiantes de doctorado. // Anales de Documentación. Universidad de Murcia. 2 (1999) 237-258.

Benito Morales, F. (1997). Información documental y aprendizaje. Bilbao : Gobierno Vasco.

Benito Morales, F. (1998). Educación documental: modelo para la adquisición de habilidades de información. // Educación y Biblioteca. 92 (1998) 35-38.

Benito Morales, F. (2000). Nuevas necesidades, nuevas habilidades. Fundamentos de la alfabetización en información. // GOMEZ HERNÁNDEZ, J. A. (coord..) Estrategias y modelos para enseñar a usar la información. Murcia : KR., 2000.

Bernhard, P. (1997). Formation à la maîtrise de l'information. URL: <http://tornade. ere.umontreal.ca/ bernh/AAFD.97/AAFD.index>. Consulta: septiembre 1999.

Bernhard, P. (1998). Apprendre à maîtriser l'information : des habiletés indispensables dans une société du savoir. // Education et francophonie. 26 : 1 (1998). URL: <http://www.acelf.ca/revue/XXVI-1/articles/09-bernhard.html>.

Bren, B. ; Hillemann, B. ; TOP, V. (1998). Effectiveness of hands-on instruction of electronic resources. // Research Strategies. 16 : 1 (1998) 41-51.

Bretelle-Desmazieres, D. (1998) Aperçu des caractéristiques des formations à l'usage de l'information dans l'enseignement supérieur français. Education et francophonie. XXVI, 1. <URL: <http://www.acelf.ca/revue/XXVI-1/articles/11-bretelle.html>.

Caspers, J. S. (1999). Hand-on instruction across the miles: Using a web tutorial to teach the Review Research Process. // Research Strategies. 16 : 3 (1999) 187-197.

Conferencia de Rectores de las Universidades Españolas (2000). Informe Universidad 2000. URL: <http://www.crue.upm.es/informeuniv2000.htm>. Consulta: abril de 2000.

Cornellá, A. (1998). La cultura de la información como institución previa a la Sociedad de la Información. // Anuari SOCADI de Documentación e Información. 1998. 
De la Mano González, M.; Moro Cabero, M. (1998). Los nuevos retos de la formación de usuarios: a la conquista del usuario virtual. // JORNADAS ESPAÑOLAS DE DOCUMENTACIÓN (6 ${ }^{a}$. 1998. Valencia). Los sistemas de información al servicio de la sociedad. Valencia: FESABID, 1998. P. 635-640

Dewald, N. ; Scholz-Crane, A. ; Booth, A. ; Levine, C. (2000). Information Literacy at a Distance: Instructional Design Issues.// Journal of Academic Librarianship. 26 : 1 (2000) 33-44.

EDUCATE Consortium (1998). Into Info. <URL: <http://educate.lib.chalmers.se /index.html>. Consulta: mayo de 2000.

Esparó, R. (2000). Biblioteca e innovación docente: la participación de la biblioteca de la Universitat Pompeu Fabra en el proyecto Campus Global. Rebiun Seminario Barcelona. La biblioteca al servicio de la docencia y la investigación. URL: <http://biblio.uoc.es/cas/rebiun/jornada.htm>. Consulta: mayo de 2000.

Fenske, R. ; Roselle, A. (1998). Proving the efficacy of library instruction evaluation. Research Strategies. 16 : 3 (1998) 175-185.

Fourie, I. ; Van Niekerk, D. (1999). Using portfolio assessment in a module in research information skills. Education for Information. 17, 1999, 333-352.

Gomez Hernández, J. A. (1996). La formación documental en los planes de estudio de los estudiantes universitarios de primer, segundo y tercer ciclo de la Universidad de Murcia. // IX Jornadas Bibliotecarias de Andalucía. Granada: Asociación Andaluza de Bibliotecarios, 1996. P. 316-334.

Gomez Hernández, J. A. (2000). La alfabetización informacional y la biblioteca universitaria. Organización de programas para enseñar el acceso y uso de la información. // Gomez Hernández, J. A. (coord.) Estrategias y modelos para enseñar a usar la información. Murcia: KR., 2000.

Henri, J. ; Hay, L. (1994). Beyond the Bibliographic Paradigm. User Education in the Information Age. // 60th IFLA General conference URL: <http://www.ifla.org/IV/ ifla60/60-henj.htm>. Consulta: marzo de 2000.

Hepworth, M. (1999). A study of undergraduate information literacy and skills: the inclusion of information literacy and skills in the undergraduate curriculum. 65th IFLA Council and General Conference. <URL: <http:/www.ifla.org/IV/ifla65/papers/107124e.htm>. Consulta: marzo de 2000.

Merino, A. ; Rufi, J. (2000). Un nuevo reto para las bibliotecas universitarias: la colaboración con la docencia y la investigación: El caso de la Universitat de Girona.// Rebiun Seminario Barcelona. La biblioteca al servicio de la docencia y la investigación. <URL: <http://biblio.uoc.es/cas/rebiun/jornada.htm> [Consulta: mayo de 2000]

Nuñez, L. (2000). Dossieres electrónicos en la biblioteca de la Universitat de Barçelona. // Rebiun Seminario Barcelona. URL: <http://biblio.uoc.es/cas/rebiun/jornada.htm>. Consulta: mayo de 2000.

Oberman, C. (1998). The Institute for Information Literacy. URL: <http://www.ala.org/ acrl/iiltrain.html>. Consulta: noviembre de 1999.

Scire. $7: 2$ (jul.-dic. 2001) 53-83. 
Oker-Blom, T. (1998). Integration of Information Skills In Problem Based Curricula. // 64th IFLA General Conference, 1998. URL: <http://www.ifla.org/IV/ifla64/142112e.htm>. Consulta: marzo 2000.

Olvera Lobo, D. ; García Caro, C. (2000). Presencia del área de Biblioteconomía y Documentación en otras titulaciones en las Universidades españolas. // V Encuentro EDBICIC. Granada : Facultad de Biblioteconomía y Documentación, 2000. p. 127-151.

Pasadas, C. (2000). Formación de usuarios y biblioteca universitaria: otro planteamiento. XI Jornadas bibliotecarias de Andalucía. Granada, : [s.n.], 2000.

Pérez, A. ; Serrano, J. ; Enrech, M.0 ; Soler, N. (2000). Bibliotecas y centros de documentación virtuales en la nueva era de la sociedad de la información: La Biblioteca Virtual de la UOC. // ONLINE EDUCA MADRID. URL: <http://cvc.cervantes.es/ obref/formacion_virtual/edicion_digital/perez.htm>. Consulta: junio de 2000.

Perez Diez, A. V. (1997). Perfil y nivel de satisfacción de los usuarios del OPAC de una biblioteca universitaria. Madrid : CINDOC, 1997.

Rader, H.B. (1999). Faculty-Librarian Collaboration in Building the Curriculum for the Milllenium: The US Experience.// IFLA Journal. 25 : 4 (1999) 209-213. (Versión actualizada de la comunicación al 64th Congreso IFLA: La colaboración entre el personal docente e investigador y los bibliotecarios a la hora de elaborar planes de estudio para el próximo milenio: La experiencia en los Estados Unidos. <URL: <http://www.ifla.org/ifla64/040-112s.htm>. Consulta: febrero de 2000.

Rader. H. B. (2000). Alfabetización informacional en el contexto del servicio de referencia. Preparándonos para el futuro. // Anales de Documentación. 3 (2000) 209-216.

REBIUN (1997). Normas y directrices para bibliotecas universitarias. URL: <http://www2.uji.es/rebiun/normasbibliotecas.html>. Consulta: 01-2000.

Rhodes, H. ; Chelin, J. (2000). Web-based user education in UK university libraries. Results of a survey. // Program. 34 : 1 (2000) 59-73.

Roselle, A. (1997). Using the ALA's "Evaluating Library Instruction", 1996. // Journal of Academic Librarianship. 5 (1997) 390-397.

Rovira, C. (1999). Documents hipertextuals per a entorns virtuals d'aprenentatg. // DigitHUM. 1 (1999). URL: <http://www.uoc.es/humfil/digithum/digithum1/crovira/croviraf.htm>.

Sangrá, A. (2000). El acceso a la biblioteca desde el Aula: un recurso de valor para la docencia. Rebiun Seminario Barcelona. La biblioteca al servicio de la docencia y la investigación. <URL: <http://biblio.uoc.es/cas/rebiun/jornada.htm>. Consulta: 05-2000.

Sastre Miralles, N. (2000). Productos y servicios para la formación de usuarios de bibliotecas universitarias: el uso de bases de datos en entornos web.// Jornadas Españolas de Documentación. Bilbao: Fesabid, 2000. 411-418.

SCONUL (1999). Aptitutes para el acceso y uso de la información en la enseñanza superior: La postura de SCONUL. (Trad. de Cristóbal Pasadas Ureña, estará disponible en el web de la Asociación Andaluza de Bibliotecarios, URL: 〈http://www.aab.es〉.

Smith, D. (1996). Evaluating library instruction: sample questions, forms, and strategies for practical use. American Library Association, 1996. 
Smith, D. (2000). Definitions of Information Literacy and Related Terms. University of South Florida. <URL: <http://nosferatu.cas.usf.edu/lis/il/definitions.html>. Consulta: 7/2/2000.

Soler, N. ; Maniega, D. (2000). La integración de la Biblioteca en el aula: la Estantería Virtual en las asignaturas de la Universitat Oberta de Catalunya. // Rebiun Seminario Barcelona. La biblioteca al servicio de la docencia y la investigación. <URL: <http://biblio.uoc.es/cas/rebiun/jornada.htm>. Consulta: mayo de 2000.

Special Librarian Association (1996). Competencias para bibliotecarios especializados del siglo XXI. URL: <http://www.sla.org/professional/competency.html<. Consulta: noviembre 1999.

Stamatoplos, A. ; Mackoy, R. (1998). Effects of Library Instruction on University Students' Satisfaction with the Library: A Longitudinal Study. // College \& Research Libraries, 59 : 4 (1998) 323-334.

Stein, L.L. ; Lamb, J. M. (1998). Not just another BI : Faculty-Librarian Collaboration to Guide Students through the Research Process. // Research Strategies. 16 : 1 (1998) 29-39.

Stewart, S.L. (1998). Assessment for library instruction: The Cross/Angelo Model. // Research Strategies. 16 : 3 (1998) 165-174.

Tobin, T. ; Kesselman, M. (1999). Evaluation of web-based library instruction programs. // 65th IFLA Council and General Conference. <URL: <http:/www.ifla.org/IV/ifla65/ papers/106-163e.htm>. Consulta: marzo de 2000.

UNESCO (1998). Declaración mundial sobre la Educación Superior en el siglo XXI: Visión y acción, y marco de acción prioritaria para el cambio y el desarrollo de la educación superior. URL: 〈http://www.crue.upm.es/dfunesco.htm>. Consulta: marzo de 2000].

Universidad Salamanca (1998). Programa Institucional de Calidad : Serv. Bibliotecas : Informe final. URL: <http://cts.usal.es/picprincipal/primerafase/inffinalbibliotecas .pdf $>$.

Universitat Autonoma de Barcelona (2000). Autoinforme d'avaluació del servei de Biblioteques. URL: <http://www.bib.uab.es/avaluacio/autoinforme.htm [Consulta mayo de 2000]

Universitat Autonoma de Barcelona (2000). Avaluació de la bub: sintesi de punts forts i punts febles, i propostes de millora. URL: <http://www.bib.ub.es/bub/avalua/avalua.htm>. Consulta: 15-1-00.

University Of Newcastle. Netskills (1998). Tonic. <URL: <http://www.netskills.ac.uk/TonicNG/cgi/sesame?tng> .

Ury, C. J. ; Meldrem, J. A. ; Johnson, C. V. (1999). Academic Library Outreach Through Faculty Partnerships and Web-Based Research Aids. // Reference Librarian. 67 : 68 (1999) p. 243-256.

Scire. $7: 2$ (jul.-dic. 2001) 53-83. 